\title{
Intelligent Wind Power Smoothing Control using Fuzzy Neural Network
}

\author{
Faa-Jeng Lin $^{1 *}$, Shih-Gang Chen ${ }^{1}$, and Jin-Kuan Chang ${ }^{1}$ \\ ${ }^{1}$ Department of Electrical Engineering, National Central University, Taoyuan 32001, Taiwan
}

\begin{abstract}
An intelligent wind power smoothing control using fuzzy neural network (FNN) is proposed in this study. First, the modeling of wind power generator and the designed battery energy storage system (BESS) are introduced. The BESS is consisted of a bidirectional interleaved DC/DC converter and a 3-arm 3-level inverter. Then, the network structure of the FNN and its online learning algorithms are described in detail. Moreover, actual wind data is adopted as the input to the designed wind power generator model. Furthermore, the three-phase output currents of the wind power generator are converted to dq-axis current components. The resulted q-axis current is the input of the FNN power smoothing control and the output is a gentle wind power curve to achieve the effect of wind power smoothing. The difference of the actual wind power and smoothed power is supplied by the BESS. Comparing to the other smoothing methods, a minimum energy capacity of the BESS with a small fluctuation of the grid power can be achieved by the FNN power smoothing control. In the experimentation, a digital signal processor (DSP) based BESS is built using two TMS320F28335. From the experimental results of various wind variation sceneries, the effectiveness of the proposed intelligent wind power smoothing control is verified.
\end{abstract}

\section{Introduction}

In recent years, global warming caused by emissions of greenhouse gases has hugely attracted the attention of governments and general public. Therefore, the development of renewable energy resources (RESs) to cope with the increasing demand for electricity and to reduce the emissions of greenhouse gases has become an important topic especially for the most cost-effective wind energy [1]. Thus, many large-scale wind power plants have been built for electrical power generation. However, wind power in many places though rich but are vulnerable to seasonal and weather influence resulted in the variation of wind energy output. Since the wind speed is random in nature, the wind power generation system should be designed to track the maximum power point of the wind turbines [2]. In addition, if a large number of wind turbines or wind farms are directly connected to the power system, the need to maintain the power and load balancing in terms of the power system stability at all times and to ensure a smooth supply of electricity owing to an instantaneous change of wind power becomes a very important issue $[1,2]$. On the other hand, RERs such as wind energy can't directly replace the existing centralized electric energy technologies. The centralized electric power plants are by far well established, while the new developed RESs are not sufficiently developed to meet the total energy demand. Therefore, it is rational to infuse RERs into existing grids gradually by using of the smart grid and power electronics technologies, and transform the power system over time [3].

There are several methods that can be used to gentle wind power fluctuations on the grid. The simplest and cheapest solution involves the use of the pitch control of the blades [4]. However, the rapid change in the blade pitch is likely to cause torque pulsation of the wind turbine. Since the blade usually has a large inertia, the torque pulsation will have a direct effect on the gear box resulted in susceptible damage on the shaft and gearbox of the wind turbine. With the development of new energy storage technology, the use of energy storage systems to alleviate fluctuations of wind power on the grid has been taken gradually in many wind farms. Currently, the most commonly adopted energy storage systems include hydro pump storage, compressed air energy storage, flywheel storage [5], superconducting magnetic energy storage $[6,7]$, super capacitor storage $[8,9]$ and battery energy storage [10], etc. Moreover, the use of battery energy storage system (BESS) to reduce the volatility of the output power of wind farm with various power smoothing control methods is an important research topic [10-13]. Most of the researches using a first-order low-pass filter to track the waveform of the wind farm output power, while the difference between the original power waveform and the smoothed power waveform is compensated by the BESS [10]. However, the performance of the first-order low-pass filter depends entirely on its time constant. Using a large time constant results in a better smoothing of the output power of the wind farm but large BESS capacity is

"Corresponding author: linfj@ee.ncu.edu.tw 
required. Conversely, when the time constant is small, the required BESS capacity decreases; however, the resulted smoothing effect could be unacceptable. Therefore, the compromise between the smoothing effect of the power curve and the capacity of the BESS is necessary; it can achieve the savings in the energy storage capacity while allowing the power curve within an acceptable range to improve the power quality. Several methods have been proposed to adjust the smoothing effect of the power curve. Examples are the adjusting of the time constant of a resilient low-pass filter using two-time-scale coordination [11], a duallayer control strategy consisting of a fluctuation mitigation control [12], and application of the concept of automatic segmentation moving average method [13]. These control methods can enable the BESS effectively managing the impact of output power variation of the wind farm.

Several intelligent control methods, such as fuzzy and neural network (NN), have been used as wind power smoothing control methods [5, 14]. In [5], an adaptive linear neuro-based control with a flexible learning rate was proposed to mitigate the power fluctuation of a wind farm. In [14], the use of fuzzy control rules to adjust the parameters of Kalman Filter was proposed to smooth the output power fluctuation of a wind power generation system. However, the fuzzy control lacks the learning capacity to satisfactorily tune fuzzy rules and membership functions. Therefore, the resulted fuzzy neural network (FNN) possesses the merits capability of both fuzzy control and NN. The FNN has shown to obtain successful results in various control applications $[15,16]$.

In this study, an FNN is adopted for the development of wind power smoothing control. Actual wind data from the wind farm built in Penghu archipelago, Taiwan, is adopted as the input signal of the designed wind power generator model in this study. Then, the three-phase output currents of the wind power generator are converted to -axis current components where the -axis current represents the active power. The resulted -axis current is the input of the FNN power smoothing control. By using the excellent approximation and online training abilities of the FNN with a grid power change rate limitation, a smoothed power with very limited time delay can be obtained. Moreover, the difference of the actual wind power and smoothed power is supplied by the BESS. Therefore, using the FNN power smoothing control, a minimum energy capacity of the BESS can be achieved with acceptable power quality of the grid, i.e. the grid active power fluctuation limit per minute is set to be $10 \%$ of the rated power [17]. This paper is organized as follows. Section II illustrates the modeling of wind power generator and BESS. Section III describes the FNN smoothing architecture including the network structure of the FNN and its online learning algorithms. Section IV provides some experimental results and conclusions are given in Section V.

\section{System architecture}

\subsection{Modeling of wind power generator}

A wind turbine extracts kinetic energy from the swept area of its blades. The power in the airflow is given by

$$
P_{\text {air }}=\frac{1}{2} \rho A U^{3}
$$

where $P_{\text {air }}$ is the power from the wind; $\rho$ is the air density in $\mathrm{kg} / \mathrm{m}^{3}$; $A$ is the exposed area in $\mathrm{m}^{2}$; $U$ is the wind speed in $\mathrm{m} / \mathrm{s}$. Although Eq. (1) gives the power available in the wind, the power transferred to the wind turbine rotor is reduced by the power coefficient $C_{p}$ as follows:

$$
\begin{gathered}
C_{p}=\frac{P_{m}}{P_{\text {air }}} \\
P_{m}=C_{p} P_{\text {air }}=\frac{1}{2} \rho C_{p} A U^{3}
\end{gathered}
$$

where $C_{p}$ is the wind turbine power coefficient; $P_{m}$ is the output power of the wind turbine. A maximum value of $C_{p}$ is defined by the Betz limit, which states that a

turbine can never extract more than $59.3 \%$ of the power from an air stream. In reality, wind turbine rotors have maximum $C_{p}$ values in the range $25-45 \%$. The developed aerodynamic torque can then be calculated as

$$
T_{m}=\frac{P_{m}}{\omega_{m}}
$$

where $T_{m}$ is the torque provided by the wind turbine; $\omega_{m}$ is the speed of the wind turbine. Moreover, the dynamic equation of the generator is in the following:

$$
T_{m}=J \frac{d \omega_{e}}{d t}+B \omega_{e}+T_{e}
$$

where $T_{e}$ is the electromagnetic torque of the generator; $J$ is the moment of inertia of the generator; $B$ is the friction coefficient of the generator; $\omega_{e}$ is the speed of the generator. Assume the generator is direct driven by the wind turbine, then

$$
\left(T_{m}-T_{e}\right)\left(\frac{1}{J S+B}\right)=\omega_{e}
$$

Thus, the available output power of the generator can be represented as:

$$
\eta \omega_{m} T_{m}=\omega_{e} T_{e}=P_{\text {wind }}
$$

where $\eta$ is the efficiency of the generator.

In this study, the model of wind power generator with $2 \mathrm{~kW}$ is established using Power SIM (PSIM) with $\eta$ setting as 0.95 and $C_{p}$ setting as 0.4 as shown in Fig. 1. Three operating modes of the wind power generator are: (1) maximum power point tracking (MPPT) mode: when $P_{\text {wind }}<P_{\max }$, the wind power generator is operated at maximum power point; (2) constant power mode: when the wind speed is too high and the output power exceeds the maximum output power $\left(P_{\max }\right), P_{\text {wind }}$ is required to maintain at $P_{\max }$; (3) brake mode: when the wind speed exceeds the maximum set speed, the wind turbine must 
be operated in brake mode to avoid damaging the wind turbine mechanical structure. Moreover, to verify the effectiveness of the PSIM model, actual wind data from the wind farm built in Penghu archipelago, Taiwan, is adopted as the input signal of the designed wind power generator model as shown in Fig. 2.

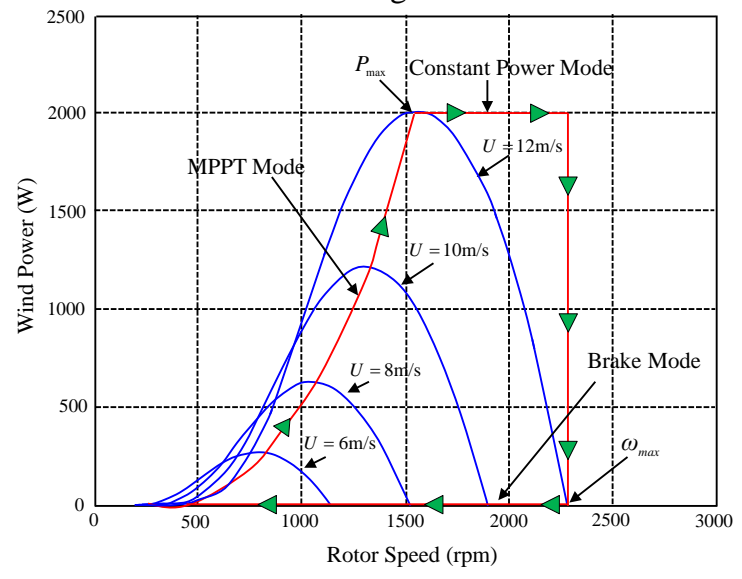

Fig. 1. Characteristics of wind power generator and operating modes.
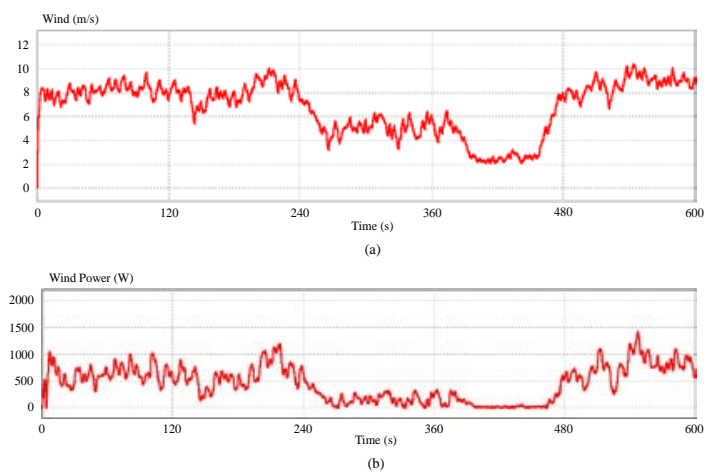

Fig. 2. PSIM simulation of wind power generator for (a) Profile of actual wind speed. (b) Output power of wind turbine generator.

\subsection{Battery energy storage system}

In this study, a BESS with two-stage circuit architecture is developed as a wind power power smoothing control as shown in Fig. 3. The first stage is a bidirectional interleaved DC-to-DC converter [18-19] and is responsible for the two-way power transmission between the battery terminal and the DC bus and the control of DC bus voltage $v_{d c}$. The second stage is a three-level neutral-point clamped (NPC) inverter [20] and is responsible for supplying the power difference of the actual wind power and smoothed power will be supplied by the BESS. The BESS and the wind power generation emulator are connected to the grid as shown in Fig. 3. Moreover, in Fig. 3, $i_{g a}, i_{g b}, i_{g c}$ are the threephase output currents of the wind power generator; $i_{\text {oa }}$, $i_{o b}, i_{o a}$ are the three-phase output currents of the DC/AC inverter; $v_{d c}^{*}$ and $v_{d c}$ are the DC bus voltage command and DC bus voltage; $v_{d 1}$ and $v_{d 2}$ are the half high voltage and half low voltage of the DC bus voltage; $i_{b a t}^{*}$ and $i_{b a t a}, i_{b a t b}, i_{b a t c}$ are the input current command and converter input currents of the of the interleave DC/DC converter; $v_{\text {bata }}^{*}, v_{\text {batb }}^{*}, v_{\text {batc }}^{*}$ are the PWM voltage commands of the interleave DC/DC converter; $v_{a}^{*}, v_{b}^{*}$, $v_{c}^{*}$ are the PWM voltage commands of the DC/AC inverter; $v_{a}, v_{b}, v_{c}$ are the three-phase voltages of the grid; $v_{q}^{*}, v_{d}^{*}, v_{0}^{*}$ are the $d q 0$-axis PWM voltage commands of the DC/AC inverter; $i_{q g}^{*}$ and $i_{q g}$ is the $q$ axis output current command and $\boldsymbol{q}$-axis output current of the wind power generator, i.e. the active power component; $i_{d g}$ is the $d$-axis output current of the wind power generator, i.e. the reactive power component; $i_{d o}^{*}$, $i_{q o}^{*}, i_{0 o}^{*}$ and $i_{d o}, i_{q o}, i_{0 o}$ are the $d q 0$-axis output current commands and $d q 0$-axis output currents of the DC/AC inverter; $\theta_{\mathrm{i}}$ is the synchronous angle obtained from PLL. The axis conversion between the $i_{\text {oa }}, i_{o b}, i_{o a}$ and $i_{d o}, i_{q o}, i_{0 o}$ and $v_{q}^{*}, v_{d}^{*}, v_{0}^{*}$ and $v_{a}^{*}, v_{b}^{*}, v_{c}^{*}$ are shown in the following:

$$
\left[\begin{array}{l}
i_{d o} \\
i_{q o} \\
i_{0 o}
\end{array}\right]=\frac{2}{3}\left[\begin{array}{ccc}
\cos \theta_{i} & \cos \left(\theta_{i}-\frac{2 \pi}{3}\right) & \cos \left(\theta_{i}+\frac{2 \pi}{3}\right) \\
\sin \theta_{i} & \sin \left(\theta_{i}-\frac{2 \pi}{3}\right) & \sin \left(\theta_{i}+\frac{2 \pi}{3}\right) \\
\frac{1}{2} & \frac{1}{2} & \frac{1}{2}
\end{array}\right]\left[\begin{array}{l}
i_{o a} \\
i_{o b} \\
i_{o c}
\end{array}\right]
$$

$$
\left[\begin{array}{c}
v_{a}^{*} \\
v_{b}^{*} \\
v_{c}^{*}
\end{array}\right]=\left[\begin{array}{ccc}
\cos \theta_{i} & \sin \theta_{i} & 1 \\
\cos \left(\theta_{i}-\frac{2 \pi}{3}\right) & \sin \left(\theta_{i}-\frac{2 \pi}{3}\right) & 1 \\
\cos \left(\theta_{i}+\frac{2 \pi}{3}\right) & \sin \left(\theta_{i}+\frac{2 \pi}{3}\right) & 1
\end{array}\right]\left[\begin{array}{c}
v_{q}^{*} \\
v_{d}^{*} \\
v_{0}^{*}
\end{array}\right]
$$

For the bidirectional interleaved DC-DC converter, the operating modes include boost mode and buck mode. The former corresponds to the battery discharge state, and the latter corresponds to the battery charge state. Average current control method is adopted where the difference of the DC bus voltage command $v_{d c}^{*}$ and DC bus voltage $v_{d c}$ is regulated by a proportional and integral (PI) controller to produce the battery charge current command $i_{b a t}^{*}$. Then, the current command $i_{b a t}^{*}$ is divided by three for the three arms of the interleaved DC/DC converter, and the differences between the current command and the sensed phase current $i_{\text {bata }}, i_{\text {batb }}$ , $i_{\text {batc }}$ are regulated via individual PI controller to generate the control signal commands $v_{\text {bata }}^{*}, v_{\text {batb }}^{*}, v_{\text {batc }}^{*}$ 
for pulse width modulation (PWM). When the current $i_{\text {bat }}^{*}$ command is positive, the circuit operates in boost mode, and the battery is discharged. Conversely, when the current $i_{b a t}^{*}$ command is negative, the circuit operates in buck mode, and the battery is charged. For the threelevel NPC inverter, it is controlled by the $d q 0$-axis current control. The $d$-axis current control is responsible for the reactive power control by using the reactive power current command $i_{d o}^{*}$ and is set to be zero. The $q$-axis current control is responsible for the active power control by using the active power current command $i_{q o}^{*}$, which is the difference between the output of the FNN $i_{q g}^{*}$ and

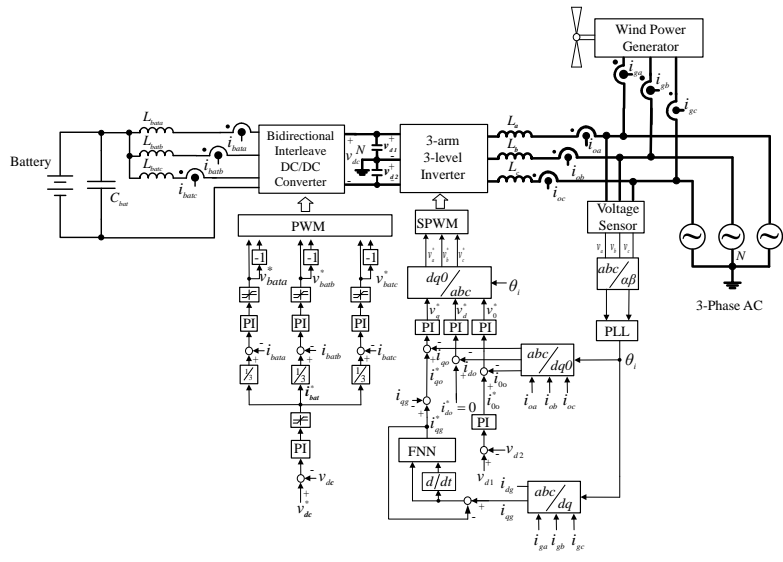

Fig. 3. BESS with intelligent wind power smoother.

the active power component of the wind power generator $i_{q g}$. In addition, the 0 -axis current control is responsible for the balance of the upper half DC bus voltage $v_{d 1}$ and the lower half DC bus voltage $v_{d 2}$ by using a PI controller to generate the 0 -axis current command $i_{0 o}^{*}$. The individual difference between the current command $i_{d o}^{*}, i_{q o}^{*}, i_{0 o}^{*}$ and the current $i_{d o}, i_{q o}, i_{0 o}$ is regulated via three PI controllers to generate the respective $d q 0$-axis voltage command $v_{q}^{*}, v_{d}^{*}, v_{0}^{*}$. Then $v_{q}^{*}, v_{d}^{*}, v_{0}^{*}$ is converted to voltage command $v_{a}^{*}, v_{b}^{*}, v_{c}^{*}$ in $a b c$-axis for sinusoidal PWM (SPWM) by using the synchronous angle $\theta_{\mathrm{i}}$.

\section{Fuzzy neural network power smoothing control}

Owing to the excellent approximation and online training abilities of the FNN, an FNN is adopted in this study for the wind power smoothing control. Using the FNN power smoothing control and considering the constraint of grid power change rate, a smoothed power with very limited time delay can be obtained. Since the difference of the actual wind power and smoothed power is supplied by the BESS, thus, the minimum capacity of the BESS can be achieved with acceptable power quality of the grid. The network structure of the FNN and its online learning algorithms are introduced in this section.

\subsection{FNN}

A four-layer FNN as shown in Fig. 4, which comprises the input (the $i$ layer), membership (the $j$ layer), rule (the $k$ layer), and output layer (the $o$ layer), is adopted to implement the FNN power smoothing control in this study. The signal propagation and the basic function in each layer of the FNN are introduced as follows: Layer 1-Input Layer: For every node $i$ in this layer, the net input and the net output are represented as

$$
\begin{gathered}
\operatorname{net}_{i}^{1}(N)=x_{i}^{1} \\
y_{i}^{1}=f_{i}^{1}\left(\operatorname{net}_{i}^{1}(N)\right)=\operatorname{net}_{i}^{1}(N), i=1,2
\end{gathered}
$$

where $x_{1}^{1}=e(t) ; x_{2}^{1}=\dot{e}(t) ; N$ denotes the number of iterations.

Layer 2-Membership Layer: In this layer, each node performs a membership function and the Gaussian function is adopted as the membership function. For the $j$ th node

$$
\begin{gathered}
\operatorname{net}_{j}^{2}(N)=-\frac{\left(x_{i}^{2}-m_{i j}\right)^{2}}{\left(\sigma_{i j}\right)^{2}} \\
y_{j}^{2}(N)=f\left(\operatorname{net}_{j}^{2}(N)\right)=\exp \left(\operatorname{net}_{j}^{2}(N)\right), j=1,2, \ldots, n
\end{gathered}
$$

where $m_{i j}$ and $\sigma_{i j}$ are the mean and the standard deviation, respectively, of the Gaussian function in the $j$ th term of the $i$ th input linguistic variable $x_{i}^{2}$ to the node of layer 2 , and $n$ is the total number of the linguistic variables with respect to the input nodes.

Layer 3-Rule Layer: Each node $k$ in this layer is denoted by $\Pi$, which multiplies the input signals and outputs the result of product. For the $k$ th rule node

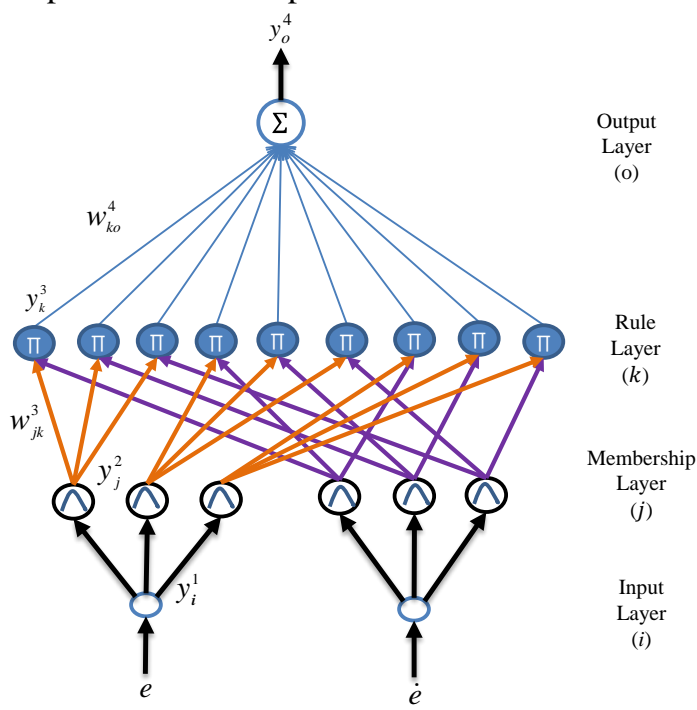

Fig. 4. Structure of four-layer FNN. 


$$
\begin{gathered}
\operatorname{net}_{k}^{3}(N)=\prod_{j} w_{j k}^{3} x_{j}^{3}(N) \\
y_{k}^{3}(N)=f_{k}^{3}\left(\operatorname{net}_{k}^{3}(N)\right)=\operatorname{net}_{k}^{3}(N), \quad k=1,2, \ldots, l
\end{gathered}
$$

where $x_{j}^{3}$ are the $j$ th input to the node of layer $3 ; w_{j k}^{3}$ are the weights between the membership layer and the rule layer and are assumed to be unity; $l=(n / i)^{i}$ are number of rules with complete rule connection if each input node has the same linguistic variables.

Layer 4-Output Layer: The single node $O$ in this layer is labeled with $\Sigma$, which computes the overall output as the summation of all input signals

$$
\begin{gathered}
n e t_{o}^{4}(N)=\sum_{k} w_{k o}^{4} x_{k}^{4}(N) \\
y_{o}^{4}(N)=f_{o}^{4} n e t_{o}^{4}(N)=\operatorname{net}_{o}^{4}(N), \quad o=1
\end{gathered}
$$

where the connecting weight $w_{k o}^{4}$ is the output action strength of the $O$ th output associated with the $k$ th rule; $x_{k}^{4}$ is determined by the selected membership function and $0 \leq x_{k}^{4} \leq 1 ; y_{o}^{4}$ is the fuzzy neural network output.

\subsection{Online Parameter Training}

In order to train the FNN effectively, an online parameter training methodology, which is derived by using the gradient descent method, is proposed. This training scheme will increase the learning capability of the FNN. First, define an energy function $E$ as the following formula:

$$
E=\frac{1}{2}\left(i_{q g}^{*}-i_{q g}\right)^{2}=\frac{1}{2} e^{2}
$$

in which $e$ is the difference between $i_{q g}^{*}$ and $i_{q g}$. The detailed learning algorithms are described below.

Layer 4-Output Layer: The error term to be propagated is given

$$
\delta_{o}^{4}=-\frac{\partial E}{\partial n e t_{o}^{4}}=\left[-\frac{\partial E}{\partial e} \frac{\partial e}{\partial i_{q g}} \frac{\partial i_{q g}}{\partial y_{o}^{4}} \frac{\partial y_{o}^{4}}{\partial n e t_{o}^{4}}\right]
$$

(15)

and the weight is updated by the amount

$$
\Delta w_{k o}^{4}=-\frac{\partial E}{\partial w_{k o}^{4}}=-\frac{\partial E}{\partial y_{o}^{4}} \frac{\partial y_{o}^{4}}{\partial n e t_{o}^{4}} \frac{\partial n e t_{o}^{4}}{\partial w_{k o}^{4}}=\delta_{o}^{4} x_{k}^{4}
$$

Layer 3-Rule Layer: Since the weights in this layer are unity, only the error term in the following needs to be calculated and propagated:

$$
\delta_{k}^{3}=-\frac{\partial E}{\partial n t_{k}^{3}}=-\frac{\partial E}{\partial y_{o}^{4}} \frac{\partial y_{o}^{4}}{\partial n e t_{o}^{4}} \frac{\partial n e t_{o}^{4}}{\partial y_{k}^{3}} \frac{\partial y_{k}^{3}}{\partial n e t_{k}^{3}}=\delta_{o}^{4} w_{k o}^{4}
$$

Layer 2-Membership Layer: The error term is computed as follows:

$$
\begin{aligned}
\delta_{j}^{2} & =-\frac{\partial E}{\partial n e t_{j}^{2}}=-\frac{\partial E}{\partial n e t} \frac{\partial y_{o}^{4}}{\partial n e t_{o}^{4}} \frac{\partial n e t_{o}^{4}}{\partial y_{k}^{3}} \frac{\partial y_{k}^{3}}{\partial n e t_{k}^{3}} \frac{\partial n e t_{k}^{3}}{\partial y_{j}^{2}} \frac{\partial y_{j}^{2}}{\partial n e t_{j}^{2}} \\
& =\sum \delta_{k}^{3} y_{k}^{3}(N)
\end{aligned}
$$

The update laws of $m_{i j}$ and $\sigma_{i j}$ are

$$
\begin{aligned}
\Delta m_{i j} & =-\frac{\partial E}{\partial m_{i j}}=-\frac{\partial E}{\partial y_{o}^{4}} \frac{\partial y_{o}^{4}}{\partial n e t_{o}^{4}} \frac{\partial n e t_{o}^{4}}{\partial y_{k}^{3}} \frac{\partial y_{k}^{3}}{\partial n e t_{k}^{3}} \frac{\partial n t_{k}^{3}}{\partial y_{j}^{2}} \frac{\partial y_{j}^{2}}{\partial n e t_{j}^{2}} \frac{\partial n e t_{j}^{2}}{\partial m_{i j}} \\
& =\delta_{j}^{2} \frac{2\left(x_{i}^{2}-m_{i j}\right)}{\left(\sigma_{i j}\right)^{2}} \\
\Delta \sigma_{i j} & =-\frac{\partial E}{\partial \sigma_{i j}}=-\frac{\partial E}{\partial y_{o}^{4}} \frac{\partial y_{o}^{4}}{\partial n e t_{o}^{4}} \frac{\partial n e t_{o}^{4}}{\partial y_{k}^{3}} \frac{\partial y_{k}^{3}}{\partial n e t_{k}^{3}} \frac{\partial n e t_{k}^{3}}{\partial y_{j}^{2}} \frac{\partial y_{j}^{2}}{\partial n e t_{j}^{2}} \frac{\partial n e t_{j}^{2}}{\partial \sigma_{i j}} \\
& =\delta_{j}^{2} \frac{2\left(x_{i}^{2}-m_{i j}\right)^{2}}{\left(\sigma_{i j}\right)^{3}}
\end{aligned}
$$

The mean and standard deviation of the hidden layer are updated as follows:

$$
\begin{aligned}
& m_{i j}(N+1)=m_{i j}(N)+\Delta m_{i j} \\
& \sigma_{i j}(N+1)=\sigma_{i j}(N)+\Delta \sigma_{i j}
\end{aligned}
$$

\subsection{FNN power smoothing control}

In the power smoothing control, first, the output three-phase currents of the wind power generator are converted to $d q$-axis current components. The resulted $q$ axis current $i_{q g}$ represents the active current component of the wind power. The difference between the output of the FNN $i_{q g}^{*}$ and $i_{q g}$, i.e. $e(t)$, and it's derivative $\dot{e}(t)$ are the two inputs of the FNN power smoothing control. After that, the output signal $i_{q g}^{*}$ is generated through the feedforward structure of the FNN following by the online parameters learning of the network. This cycle is repeated every $10 \mathrm{~ms}$. Since the learning process is to minimize the difference between $i_{q g}^{*}$ and $i_{q g}$, i.e. $e(t)$, the curve of the output of FNN $i_{q g}^{*}$ will be quite similar to the curve of $i_{q g}$ with limited time delay. On the other hand, though the FNN possesses excellent approximation ability but it is not perfect, and the nonperfect $i_{q g}^{*}$ results in a more gentle wind power curve to achieve the effect of wind power smoothing. Therefore, the FNN wind power smoothing scheme not only can - The need to ensure sustainability of the power system when a large number of generating units of the DER facilities are disconnected,

- The need to ensure the possibility of isolated operation of all types of generating units at the DER facilities.

To effectively solve the problems mentioned above, it is necessary to introduce new technologies in control systems, relay protection and automation in power districts with distributed energy resources. Let us first consider the requirements for modern control, protection and automation systems in power districts with DER. effectively reduce the amount of battery capacity but also takes the power quality of the grid into account. In Fig. 3, the difference between $i_{q g}^{*}$ and $i_{q g}$ is also indicated as $i_{q o}^{*}$. When $i_{q o}^{*}$ is negative indicating 
that the output power of the wind power generator is greater than the smoothing power, the battery will absorb excess power. On the other hand, when $i_{q o}^{*}$ is positive indicating that the output power of the wind power generator is smaller than the smoothing power, the battery will discharge.


Fig. 5. Comparison of smoothing methods.(a) Average method (b) Moving average method (c) Low-pass filter method (d) FNN method (e) Enlarged responses of average method (f) Enlarged responses of moving average method (g) Enlarged responses of low-pass filter method (h) Enlarged responses of FNN method (i) SOC of average method (j) SOC of Moving average method (k) SOC of Low-pass filter method (l) SOC of FNN method.

effectively reduce the amount of battery capacity but also takes the power quality of the grid into account. In Fig. 3, the difference between $i_{q g}^{*}$ and $i_{q g}$ is also indicated as $i_{q o}^{*}$. When $i_{q o}^{*}$ is negative indicating that the output power of the wind power generator is greater than the smoothing power, the battery will absorb excess power. On the other hand, when $i_{q o}^{*}$ is positive indicating that the output power of the wind power generator is smaller than the smoothing power, the battery will discharge.

\subsection{Comparison of smoothing methods}

The main objective of the research is determine the necessary capacity of BESS for use in conjunction with a wind power generator that allows the output of combined wind power generator and BESS to meet the connected grid requirements, i.e. the fluctuation of injected power to the grid should be kept below some percentage of the rated power to maintain the grid power quality [17]. To verify the effectiveness of the proposed control strategy, simulation analyses were performed using the wind power generation model and MATLAB/SIMULINK. Actual 24 hours wind data from the wind farm built in Penghu archipelago, Taiwan, is adopted as the input signal of the designed wind power generator model.

The comparison of smoothing methods is shown in Figs. 5(a)-5(d) including the average method, the moving average method [21], the low-pass filter method [11] and the FNN method. In Figs. 5(a)-5(d), $P_{\text {wind }}$ is the actual wind power and $P_{\text {out }}$ in the smoothed power which can be calculated from $i_{q g}^{*}$. The required energy capacity of the BESS could be described by the following equation:

$$
\begin{gathered}
E_{\text {BESS }}=\operatorname{Max}\left\{\sum_{i=a}^{i=a+N}\left(\left|P_{\text {wind }}\left(t_{i}\right)-P_{\text {out }}\left(t_{i}\right)\right|\right) \Delta t\right\}, \\
P_{\text {wind }}>P_{\text {out }} \text { or } P_{\text {out }}>P_{\text {wind }}
\end{gathered}
$$

where $a$ and $a+N$ are the start and stop time of continues charging or discharging; $\Delta t$ is the sampling interval which is $1 \mathrm{~s}$. The resulted energy capacities using (23) of the various methods shown in Figs. 5(a)-(d) are shown in Table I where the average method requires the largest energy capacity of the battery and the FNN required the smallest energy capacity of the battery. The required power capacities of various smoothing methods are also given in Table I using the following equation:

$$
P_{\text {BESS }}=\operatorname{Max}\left\{\left|P_{\text {wind }}\left(t_{i}\right)-P_{\text {out }}\left(t_{i}\right)\right|\right\}
$$

From the data shown in Table I, the minimum power capacity of the BESS still can be obtained by the proposed intelligent smoothing method using FNN. Moreover, the responses from 13 hour to 16 hour, which are shown in Figs. 5(a)-(d), are enlarged and shown in Figs. 5(e)-(h). From the simulated results shown in Figs. 5(e)-(h), the time delay phenomena of the smoothed curves of the moving average and first-order low pass filter methods are very obvious. Only a smoothed power curve with very limited time delay and with the minimum energy capacity of the BESS can be obtained by the proposed intelligent smoothing method using FNN. Furthermore, in this study, the state of charge (SOC) estimation using Coulomb counting method [22] is adopted for the management of the active power. In addition, in the energy management of Lead-Acid battery, the ordinary minimum and maximum SOC is $10 \%$ and $90 \%$. For the comparison of various smoothing methods and considering the allowed minimum SOC, a 
BESS consisting of 30 Lead-Acid batteries with $12 \mathrm{~V} / 12 \mathrm{Ah}$ is adopted in this study. The resulted SOC responses of the average method, the moving average method, the low-pass filter method and the FNN method are shown in Figs. 5(i)-(l). From the simulated results, the SOC of the average method reaches nearly its lowest limit $10 \%$. On the other hand, there still have plenty of capacities for all the other three methods especially for the FNN method.

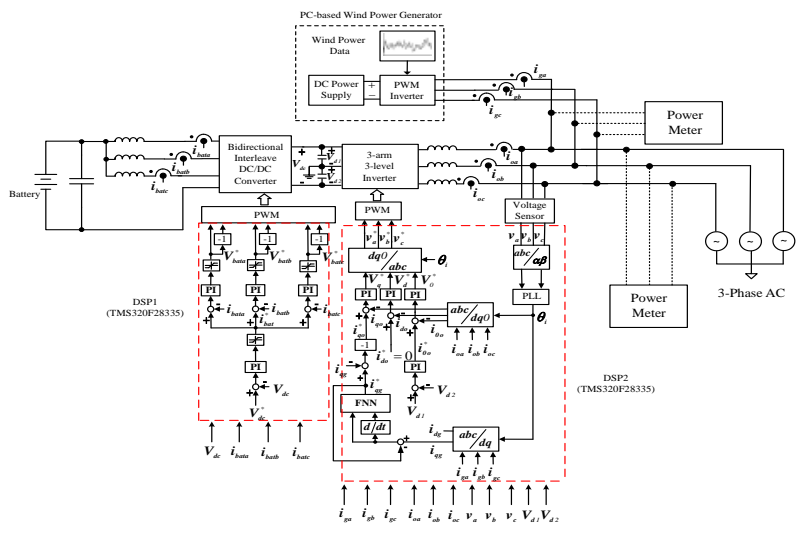

Fig. 7. DSP architecture of BESS.

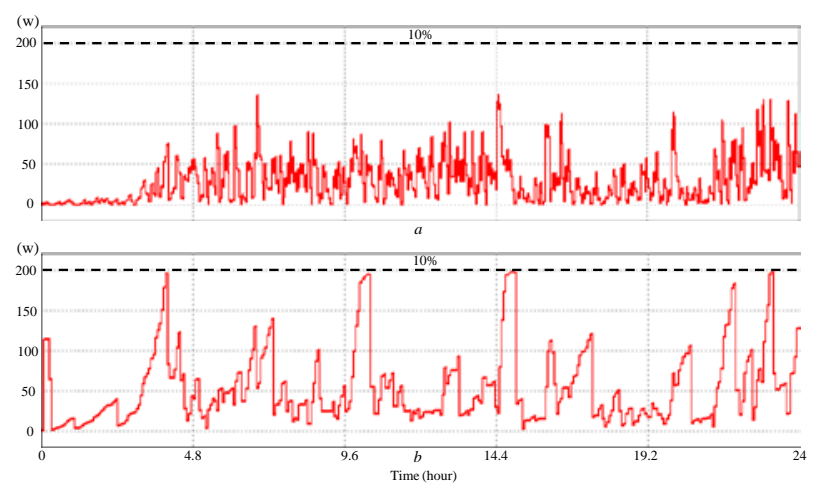

Fig. 6. Fluctuation percentage of the injected power. (a) $1 \mathrm{~min}$ average window (b) 10min average window.

To further compare the smoothing performance of various smoothing methods, the standard deviation of the smoothed power is defined as follows:

$$
\sqrt{\sum_{i=1}^{h}\left(P_{\text {wind }}\left(t_{i}\right)-P_{\text {out }}\left(t_{i}\right)\right)^{2} / h}
$$

where $h$ is the total number of sampling of 24 hours. The standard deviations of smoothed power at various smoothing methods are shown in Table II where the FNN method still has the smallest value. In addition, the grid active power fluctuation limit per minute is set to $10 \%$ of the rated power. The satisfaction of $10 \%$ grid power fluctuation limit using the proposed FNN is shown in Fig. 6, where 1min average window is shown in Fig. 6(a) and 10min average window is shown in Fig. 6(b). Therefore, the impact to the grid power quality of the FNN power smoothing control is also promised.

\section{Experimental set-up and experimentation}

\subsection{Experimental set-up}

The block diagram of the DSP-based BESS, including two TMS320F28335 control boards DSP1 and DSP2 and a PC-based wind power generator, is shown in Fig. 7. In this study, only the active power of the wind power, smoothed power and power supplied by the BESS considered. The difference of the wind power $P_{\text {wind }}$ and smoothed power $P_{\text {out }}$ is supplied by the BESS $P_{i n v}$. Therefore, in Fig. 7, the $q$-axis current control is responsible for the active power control of the BESS by using the active power current command $i_{q o}^{*}$, which is the difference between the output of the FNN $i_{q g}^{*}$ and the active power component of the wind power generator $i_{q g}$. The $d$-axis current control is responsible for the reactive power control by using the reactive power current command $i_{d o}^{*}$ and is set to be zero. Furthermore, the installed locations of the two power meters are also demonstrated in Fig. 7. The values of the two DC bus capacitors and the three filter inductors of the inverter are $1300 \mu \mathrm{F}$ and $1.6 \mathrm{mH}$ respectively.

For the $2 \mathrm{~kW}$ PC-based wind power generator, a current-controlled PWM inverter is adopted. Moreover, modeling of the wind power generator, field-orientation and synchronization algorithm are realized via Simulink. In addition, three actual wind power curves with 600s are built in the wind power generator which are the variation of the wind speed $7 \mathrm{~m} / \mathrm{s}-10 \mathrm{~m} / \mathrm{s}-12 \mathrm{~m} / \mathrm{s}-10 \mathrm{~m} / \mathrm{s}$, $9 \mathrm{~m} / \mathrm{s}-12 \mathrm{~m} / \mathrm{s}-8 \mathrm{~m} / \mathrm{s}-6 \mathrm{~m} / \mathrm{s}$ and $8 \mathrm{~m} / \mathrm{s}-10 \mathrm{~m} / \mathrm{s}-5 \mathrm{~m} / \mathrm{s}-2 \mathrm{~m} / \mathrm{s}-$ $8 \mathrm{~m} / \mathrm{s}$.

Table 1. Required energy capacity and power capacity of battery at various smoothing methods

\begin{tabular}{|c|c|c|c|c|}
\hline & Average & $\begin{array}{c}\text { Moving } \\
\text { Average }\end{array}$ & $\begin{array}{c}\text { First-order } \\
\text { Low Pass } \\
\text { Filter }\end{array}$ & FNN \\
\hline $\begin{array}{c}\text { Energy } \\
\text { Capacity } \\
\text { kWh }\end{array}$ & 2.64 & 0.576 & 0.539 & 0.43 \\
\hline $\begin{array}{c}\text { Power } \\
\text { Capacity } \\
\text { kW }\end{array}$ & 1.125 & 1.0 & 0.915 & 0.877 \\
\hline
\end{tabular}

Table 2. Standard deviation of smoothed power at various smoothing methods

\begin{tabular}{|c|c|c|c|c|}
\hline & Average & $\begin{array}{c}\text { Moving } \\
\text { Average }\end{array}$ & $\begin{array}{c}\text { First-order } \\
\text { Low Pass } \\
\text { Filter }\end{array}$ & FNN \\
\hline $\mathrm{kW}$ & 0.468 & 0.339 & 0.291 & 0.277 \\
\hline
\end{tabular}

Both the bidirectional interleaved DC/DC converter and 3-arm 3-level inverter are implemented using an intelligent power modules (SK30MLI066) manufactured by Semikron Co. with a switching frequency of $10 \mathrm{kHz}$. The capacity of the inverter is $5 \mathrm{~kW}$ and the $\mathrm{DC}$ bus voltage is $430 \mathrm{~V}$. Moreover, the battery is consisted of 30 Lead-Acid batteries with $12 \mathrm{~V} / 12 \mathrm{Ah}$. In addition, to show the effectiveness of the wind smoothing control with small number of neurons 6 and 9 are adopted at the membership and rule layers in the FNN by empirical 
rules to achieve fast dynamic responses of the smoothing control and to reduce the execution time simultaneously.

\subsection{Experimentation}

The experimental results using the proposed FNN smoothing method at the wind speed variation condition $7 \mathrm{~m} / \mathrm{s}-10 \mathrm{~m} / \mathrm{s}-12 \mathrm{~m} / \mathrm{s}-10 \mathrm{~m} / \mathrm{s}$ are shown in Fig. 8 where the wind power and the smoothing power are shown in Fig. 8(a); the measured three-phase currents at the wind power generator are shown in Fig. 8(b); the measured three-phase currents at the grid side are shown in Fig. 8(c); the measured three-phase output currents of the inverter are shown in Fig. 8(d). Moreover, the experimental results using the proposed FNN smoothing method at the wind speed variation condition $9 \mathrm{~m} / \mathrm{s}-$ $12 \mathrm{~m} / \mathrm{s}-8 \mathrm{~m} / \mathrm{s}-6 \mathrm{~m} / \mathrm{s}$ are shown in Fig. 9 where the wind power and the smoothing power are shown in Fig. 9(a); the measured three-phase currents at the wind power generator are shown in Fig. 9(b); the measured threephase currents at the grid side are shown in Fig. 9(c); the measured three- phase output currents of the inverter are shown in Fig. 9(d). Furthermore, the experimental results using the proposed FNN smoothing method at the wind speed variation condition $8 \mathrm{~m} / \mathrm{s}-10 \mathrm{~m} / \mathrm{s}-5 \mathrm{~m} / \mathrm{s}-2 \mathrm{~m} / \mathrm{s}-8 \mathrm{~m} / \mathrm{s}$ are shown in Fig. 10 where the wind power and the smoothing power are shown in Fig. 10(a); the measured three-phase currents at the wind power generator are shown in Fig. 10(b); the measured three-phase currents at the grid side are shown in Fig. 10(c); the measured three-phase output currents of the inverter are shown in Fig. 10(d). From the experimental results of various wind variation conditions, the effectiveness of the proposed intelligent wind power smoothing control is obvious. The phenomena of time delay are very limited at all test conditions. In addition, from the measured three-phase currents at the wind power generator, the measured three-phase currents at the grid side and the measured three-phase output currents of the inverter, the difference between the three-phase currents at the wind power generator and the three-phase

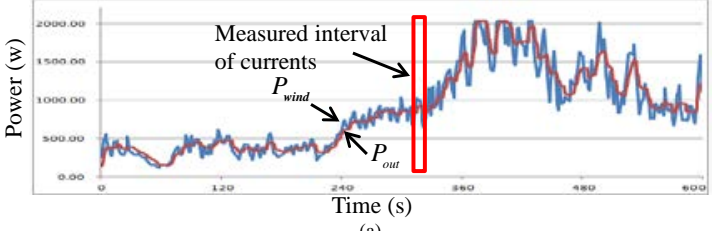

(a)
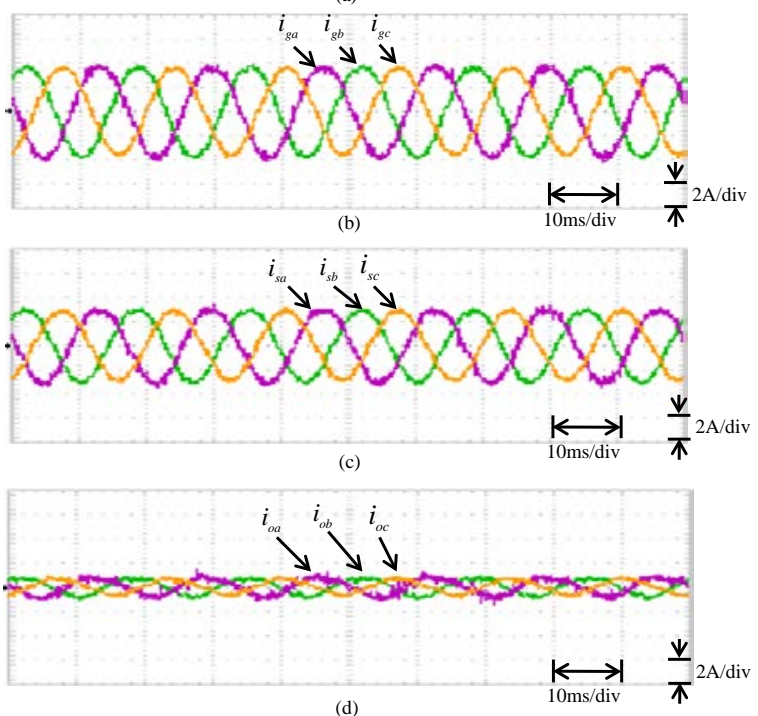

Fig. 8. Experimental results using FNN smoothing method at wind speed $7 \mathrm{~m} / \mathrm{s}-10 \mathrm{~m} / \mathrm{s}-12 \mathrm{~m} / \mathrm{s}-10 \mathrm{~m} / \mathrm{s}$. (a) Wind power and smoothing power (b) Measured three-phase currents at wind power generator (c) Measured three-phase currents at grid side (d) Measured three-phase output currents of inverter.
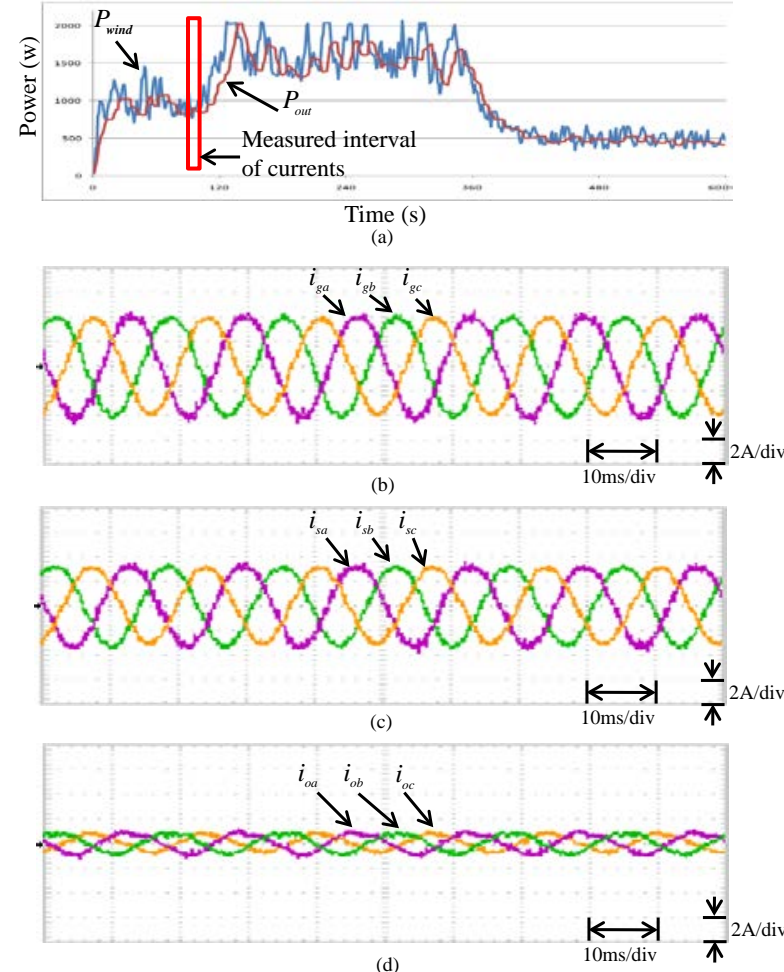

Fig. 9. Experimental results using FNN smoothing method at wind speed $9 \mathrm{~m} / \mathrm{s}-12 \mathrm{~m} / \mathrm{s}-8 \mathrm{~m} / \mathrm{s}-6 \mathrm{~m} / \mathrm{s}$. (a) Wind power and smoothing power (b) Measured three-phase currents at wind power generator (c) Measured three-phase currents at grid side (d) Measured three-phase output currents of inverter. 

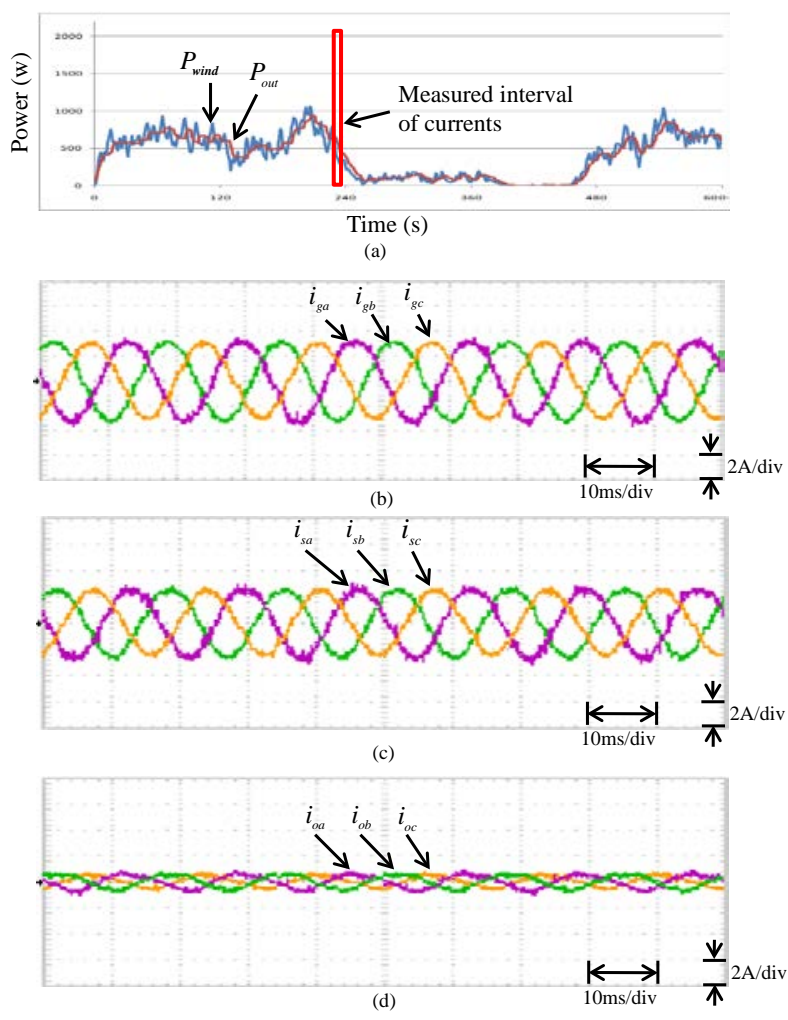

Fig. 10. Experimental results using FNN smoothing method at wind speed $8 \mathrm{~m} / \mathrm{s}-10 \mathrm{~m} / \mathrm{s}-5 \mathrm{~m} / \mathrm{s}-2 \mathrm{~m} / \mathrm{s}-8 \mathrm{~m} / \mathrm{s}$. (a) Wind power and smoothing power (b) Measured three-phase currents at wind power generator (c) Measured three-phase currents at grid side (d) Measured three-phase output currents of inverter.

currents at the grid side is compensated by the threephase output currents of the inverter at all test conditions.

\section{Conclusions}

An intelligent wind power smoothing control using fuzzy neural network (FNN) has been successfully developed in this study. By using the excellent approximation and online training abilities of the FNN, a smoothed power curve with very limited time delay has been obtained. Moreover, the difference of the actual wind power and smoothed power is supplied by the BESS. Comparing to the other smoothing methods, a minimum energy capacity of the BESS has been achieved using the FNN power smoothing control. From the experimental results of various wind variation conditions, the effectiveness of the proposed intelligent wind power smoothing control has been clearly shown. In addition, the fluctuation of injected power to the grid per minute is kept below $10 \%$ of the rated power to maintain the grid power quality at all test conditions. The major contributions of this study are: (1) the development of a BESS which is consisted of a bidirectional interleaved DC/DC converter and a 3-arm 3-level inverter; (2) the development of an intelligent wind power smoothing control using FNN; (3) the minimum energy capacity of the battery and a small fluctuation of the grid active power being achieved simultaneously by using the FNN wind power smoothing control.

\section{Acknowledgment}

This work was supported by the Ministry of Science and Technology of Taiwan through grant number: MOST 107-2923-E-008-001

\section{References}

1. E. Iyasere, M. Salah, D. Dawson, J. Wagner, and E. Tatlicioglu, IET Control Theory \& Applications 6, 526-532 (2012).

2. M. Jannati, S. Hosseinian, B. Vahidi, and G. J. Li, Renewable and Sustainable Energy Reviews 29, 158-172 (2014).

3. M. Liserre, T. Sauter, and J. Hung, IEEE Ind. Electron. Mag. 4, 18-37 (2010).

4. E. Iyasere, M. Salah, D. Dawson, J. Wagner, and E. Tatlicioglu, IET Control Theory \& Applications 6, 526 (2012).

5. M. Jannati, B. Vahidi, G. J. Li, and S. Hosseinian, IET Renew. Power Gener. 8, 659-669 (2014).

6. T. Ise, M. Kita, and A. Taguchi, IEEE Trans. on Appiled Superconductivity 15, 1915-1918 (2005).

7. S. Nomura, Y. Ohata, T. Hagita, H. Tsutsui, S. Tsuji-Iio, and R. Shimada, IEEE Trans. on Appiled Superconductivity 15, 1951-1954 (2005).

8. T. Kinjo, T. Senjyu, N. Urasaki, and H. Fujita, IEEE Trans. on Energy Convers. 21, 221-227 (2006).

9. X. Li, C. Hu, C. Liu, and D. Xu, 2008 34th Annual Conference of IEEE Industrial Electronics 2008.

10. X. Han, F. Chen, X. Cui, Y. Li, and X. Li, Energies 5, 1593-1612 (2012).

11. Q. Jiang and H. Wang, IEEE Trans. Energy Convers. 28, 52-61 (2013).

12. Q. Jiang, Y. Gong, H. Wang, IEEE Trans. Power Syst. 28, 3263-3273 (2013).

13. W. Wang, C. Mao, J. Lu, and D. Wang, Energies 6, 3392-3404 (2013).

14. X. Li, IET Renew. Power Gener. 6, 340-347 (2012).

15. F. J. Lin, K. H. Tan, D. Y. Fang, and Y. D. Lee, IET Renew. Power Gener. 7, 552-564 (2013).

16. F. J. Lin, P. H. Shieh, and P. H. Chou, IEEE Trans. Fuzzy Sys. 16, 676-692 (2008).

17. B. Fox, D. Flynn, L. Bryans, et al., IET Power Energy Ser. 7, 167-169 (2007).

18. S. Dusmez, A. Hasanzadeh, and A. Khaligh, IEEE Trans. Ind. Electron. 62, 3305-3315 (2015).

19. H. Kosai, J. Scofield, S. Mcneal, B. Jordan, and B. Ray, IEEE Trans. Power Electron. 28, 1691-1699 (2013).

20. Z. Zhang, O. C. Thomsen, and M. A. E. Andersen, IEEE Trans. Ind. Electron. 60, 1897-1906 (2013).

21. M. Sheikh, S. Muyeen, R. Takahashi, T. Murata, and J. Tamura, 2009 IEEE Bucharest PowerTech. (2009). 
22. M. Coleman, C. K. Lee, C. Zhu, and W. Hurley, IEEE Trans. Ind. Electron. 54, 2550-2557 (2007). 